\title{
Understanding Urban Gamification - Playful meaning-making in real and digital city spaces
}

\author{
Mattia Thibault
}

\begin{abstract}
This paper offers a semiotic perspective on how play is used to change the citizens' perception of the city. The paper adopts a meaningcentred approach to playfulness (a resemantisation of the surrounding environment) and to urban spaces (complex meaning-making machines). It investigates the different ways citizens can reclaim their right to the city by writing or enunciating it and the role played by play in these dynamics in the context of a ludicising culture. After engaging a few examples of urban gamification (such as flash mobs and park(ing) day) the paper also engages the digital representations of the city and how also this dimension of the urban spaces is subject to forms of gamification.
\end{abstract}

Keywords: Urban play, gamification, semiotics, park(ing) day, flash mobs, playable cities, DIY urbanism, right to the city, urban games, Pride parades, cities.

\section{Biographical notes:}

This paper is a revised and expanded version of a paper entitled Reinterpreting cities with play Urban semiotics and gamification presented at ArtsIT 2018, Braga (Portugal) 24 ${ }^{\text {th }}$ October 2018.

\section{Introduction}

Urban areas throughout history have often been playgrounds. Most of us have, at least once, played at "don't walk on the pavement lines", encountered a hopscotch chalk drawing on a sidewalk, jumped through it on one leg or interacted with the urban space in other playful ways. As the urban environment is not per se a playground, playing in the city assumes specific features. The city spaces are public, populated by passers-by, policemen, street vendors, therefore every play activity is also a public interaction that has a social and cultural dimension.

Today the occasions of playing in the city are increasing exponentially: pervasive computing allows millions to play augmented reality (AR) 
games such as Pokémon Go in the streets, while nerdy and carnivalesque practices like zombie walks offer new playful ways of occupying public spaces.

Playing in the city, however, is not simply a matter of entertainment or having fun. Situationism was maybe the first movement to point out the subversive character of playing in the city. Gilles Ivain, in his Formoulaire pour un urbanisme nouveau (Ivain 1958), underlines how a situationist approach might save the city from the modern "mental illness" of a banality driven by production and comfort. Places devoted to playfulness, argues Ivain, are able to influence strongly the citizens' behaviour and have a great force of attraction. Guy Debord's psychogeography (1957), rejecting utilitarianism, proposed alternative playful ways of crossing the city (the derive) and mapping it.

Nowadays, the idea that cities shouldn't just be smart but also playable is gaining more and more recognition. Stevens in Ludic City (2007), for example, argues for the necessity of open spaces for non-instrumental, ludic activities in city spaces, although the latter are generally disregarded by urban planners. Playable Cities, a concept developed by the Watershed in Bristol, are proposed as an alternative the technocentrism and coldness of Smart Cities (see also de Lange 2015 and Nijholt 2017). Finally, Urban Gamification (Thibault 2019) claims that urban play can be instrumental for empowering citizens and help them reappropriating public spaces.

Within this multiplicity of perspectives, this paper outlines a semiotic approach for studying urban play in the wider frame of gamification, in order to deepen our understanding on how we can use play to affect the urban spaces and on what effects this might have on the citizens and their practices. In particular, this paper focuses on outlining a meaning-centred approach to urban areas and to analyse how playful activities of reading and rewriting the city can influence the citizens' perception and interpretation of the urban environment.

\section{Playfulness as an interpretative attitude}

In order to address the role of play in the urban spaces, we need first to define what we mean with this word. This is, in fact, a tricky question. The debate on how to define play - and even if this endeavour is possible at all - is still open and produces many arguments and counterarguments. The most convincing perspectives, however, are those considering the concept of "play" more like an operational tool than an ontological definition. Wittgenstein claims that there is nothing in common between all the 
activities that we label as play if not a family resemblance (Wittgenstein 1953): any attempt of defining play, then, is actually an attempt to redefine it. Brian Sutton-Smith's rhetorics of play can be understood in this perspective: they are different ways of making sense, framing and understanding play (Sutton-Smith 1997).

If proposing a new definition of "play" would therefore be rather useless for our purpose, it will be important to try to understand what happens while playing and in particular, how playing affects the way we make sense of the world. The idea that play spurs from a different set of meaning has been advanced and described by several scholars, but its best conceptualization is to be found in the works of Juri Lotman. In the article "The place of art among other modelling systems" (Lotman 2011) which, as the title suggests, deals mainly with the cultural role of art, Lotman, exposes a restricted theory of playfulness. According to Lotman play involves the dynamic constant awareness of the possibility of alternate meanings to the one that is currently being perceived. These different meanings of the same element do not appear in static coexistence but "twinkle" while each interpretation makes up a separate synchronic slice yet retains a memory of earlier meanings and the awareness of the possibility of future ones.

Basically, Lotman suggests that play involves a resemantisation of the world - i.e. a systemic shift of its meaning. This resemantisation gives to the world a second, additional and fictional meaning, that the players perceive and interpret as such. The players, then, oscillate between two different systems of interpretation, between two different ways to make sense of the same physical reality. On the one hand, the players never give up completely their awareness of the "ordinary reality", but, on the other hand, they almost act as if the playful situation was real. From a semiotic standpoint, thus, the starting point of any playful activity is the systematic resemantisation of objects and actions, that translate the whole world (or better, a portion of it delimited by the borders of play) into the semiotic domain of play. This resemantisation, however, does not entail any serious confusion between the two domains, that are perfectly separated in the mind of the player.

Play's ability to resemantise our surroundings without the need to modify them, can be a rather important asset in any action that attempt to reappropriate alienated public spaces. The limits that citizens have in regard of their ability to act and change the urban spaces they inhabit, can be somewhat dismissed, if we act on our perception of the city and therefore our behaviour within it. We shall call this playful resemantisations of the urban spaces as acts of urban gamification. 


\section{Urban semiotics or how we make sense of the city}

We have claimed that play can be a tool for making sense of the city in a way that is alternative to that of ordinary life. In order to understand how, however, we need to engage the semiotic properties of urban areas.

Defining what is a city is notably a complex matter. The Oxford Dictionary defines it as a "large town", the latter being "A built-up area with a name, defined boundaries, and local government". Countries and international organisations define cities in different ways, sometimes according to administrative borders and nomenclatures, sometimes based on population estimates and the concept of "urban agglomeration". For a semiotic approach, however, we are especially concerned with what is interpreted as a city, with a name and, often, a "personality".

Already in 1980 Michel de Certeau in his L'invention du quotidien (De Certeau 1980) proposed to consider the city as a textual form. This parallelism - metaphorically already implicit in the expression "urban fabric" - leads de Certeau to consider the city as a real text, actualised (and transformed) by the practices of interaction and crossing of their inhabitants. The journey of the latter through the urban space, then, is nothing but an enunciation, by which the individuals take possession of the places and transforms them by introducing their own subjectivity. The city, then, is a text anything but fixed: it emerges as the result of practices of enunciation that, at the same time, actualise and deeply modify the urban spaces. In the same years, Marshall Berman, from another perspective, elaborated the idea of the city as a machine that produces meaning, a "multimedia presentation whose audience is the whole world" (Berman 1982, p. 288).

The metaphor of urban space as a text, as well as that of the city as a producer of meaning, can be found, with some distinctions, in urban semiotics. In one of the founding works of urban semiotics Ugo Volli (2005) writes that from the semiotic point of view, an expressive reality that is renewed and continually redefines itself such as the city, is defined "discourse": a signifying practice which, however, at all times projected behind itself a text. The city is alive, it changes materially and in the sense that it projects; but in every time it is stable and legible as a book

\footnotetext{
${ }^{1}$ Cf UN Data Booklet "The World's Cities in 2016" available at https://www.un.org/en/development/desa/population/publications/pdf/urbanization/the_w orlds_cities_in_2016_data_booklet.pdf
} 
The city, therefore, is not really a text, but rather acts as a text - as a text it can be read, but also approached, analysed and understood (Volli 2008) (Mastroianni 2013).

The city, just like a text, is both an organic whole - that can be understood and labelled as a unique thing - and characterized by an irreducible structural heterogeneity - a city encompasses numerous texts of smaller scale (neighbourhoods, streets, buildings, signs, street furniture, graffiti ...). All these smaller texts are interconnected by their simultaneous presence within the city, which then becomes a web of meaningful elements connected to each other (Volli 2005). This is obviously an unstable and uncertain mingling, whose metamorphoses follow different times and rhythms, from the slow construction of new neighbourhoods to the quick work of street-writers and the ephemeral presence of advertising posters. This dual nature, of homogeneous text and of container of textualities of a smaller scale, is recognised by authors semioticians such as Lotman (1998) and Cervelli and Sedda (2006) and leads to a fundamental disappearance of a clear distinction between text and context. If, on the one hand, the elements of larger size can become the context for those, incorporated, of smaller size (a neighbourhood becomes the context of a building, a square that of a monument), the relationship between text and context is not limited to a simple relationship of incorporation, and therefore, on the other hand, it is possible that the objects of a smaller size, but with a greater symbolic efficacy, can become the context for largerscale objects: "iconic" buildings and monuments are able to lessen the meaning of all that it is around them, creating a semiotic void that allows them to "shine". Urban areas, then, appear as a polylogical set to which we have to add also all the objects moving through it: goods, trucks, cars and the inhabitants of the city themselves, which cross its spaces and are distributed in different parts of the city giving meaning to the metropolitan landscapes.

Text-cities, as already implied by de Certeau, are inevitably polyphonic texts, which elude any attempt of standardization by the political, economic or religious powers. The city-enunciated is the product of countless authors, eras and conceptions of urban spaces, to which correspond a great number of different strategies - sometimes even conflicting - which meet, collide, mingle and overwrite each other in the city. Different powers in the city aim at leaving traces in the urban fabric. The religious and political power often faced each other creating sumptuous buildings to display their wealth and importance. Modern rival companies compete for the ownership of the highest skyscraper. Terrorist attacks attempt to erase certain symbolic buildings from the city altogether. The urban areas, then, become places whose elements are 
pervaded by an antagonistic tension: competing to obtain dominant positions (centrality, verticality, passages), attention (traffic) and prestige. This tension, however, is generally petrified in the buildings and streets of the city, which freeze them in a spatial arrangement. This incessant internal tension of urban spaces entails a constant transformation: the city is a variable text, alive, never identical to itself, a text that retains elements of its past (text as testis, Latin for witness) and interweaves them with those of the present (text as textus, Latin for fabric) in a set often heavily layered and ontologically complex (Volli 2008).

This kaleidoscopic web of meaningful elements features also its own hierarchy: an ideological stratification that gives greater emphasis and meaning to the buildings of the political and religious power, to monuments and "landmarks" and, instead, relegates to a marginal role the communicative traces of most of the inhabitants, which can only count on their ephemeral presence, or recur to billboards, signs, graffiti.

This ideological stratification is accompanied by a historical one, which moves at different speeds: some elements of the city can last for thousands of years (the topography, the orientation of the street map), other for centuries (buildings, streets and monuments), other for years (signs and elements of street furniture) or weeks (posters and display cases), down to the momentary presence of the inhabitants themselves: every look at the city, then, essentially captures just a section of it.

If the city is certainly the product of a culture, on the other hand it is itself also a producer of culture. There is a city-enunciated, but also a cityenunciator, which produces meaning and tells about the society and the people who inhabit it.

Focusing on this specific characteristic of urban spaces, allows us to emphasize the ways in which they convey meaning, they communicate with those who inhabit them, walk them, live them. On the one hand, the meanings conveyed by a city profoundly influence the actions of their inhabitants, through obligations, prohibitions and directions. On the other hand, cities transform people into citizens: they make them urban and polite - words that come respectively from the Latin and Greek words for "city".

The city, then, can be considered as a complex communicating machine (Mastroianni 2013), object of discourses and analysis that interpret it providing identity and consistency, but, at the same time, it is itself the subject of discourses and an important producer of meaning and culture. 


\section{Reading, interpreting and re-interpreting the city}

To live and move through the city means, first of all, to be able to read and to interpret it. The experiential aspect of the city becomes even more important if, as in our case, we want to focus on the relationship between playfulness and urban spaces: gamifying city spaces is, first of all, an operation of interpretation and reinterpretation. In this paragraph, we will focus briefly on how the city is read by its inhabitants and which mechanisms and actions are necessary to re-write it.

To read a rich text such as a city, it is necessary to choose some saliences - which items are significant, and which are trivial - and then to draw isotopies between them, in order to give a unique and organic meaning to the heterogeneous whole in which these diverse elements are immersed. Selecting the saliences, however, is not enough to be able to move consciously within the city. If it is true that in a social environment everything becomes a sign of its possible use, on the other hand, many objects are used differently by different individuals or at different times. Some objects may even be "reinvented" through practices contradictory of their constituent strategic purpose. We should talk, then, of possible uses, in the plural form, thus implying the need for a second operation of selection and interpretation. The selection of a specific use between many possibilities is guided by a "urban semiotic competence" (Volli 2005): the ability to correctly interpret what the city tells us. This competence is rather pragmatic, as it will guide the inhabitants in their tasks for experiencing the city. The city itself can hinder or facilitate the use of this competence in virtue of its legibility - the urban characteristic of assisting people in creating their mental maps and fostering wayfinding (Lynch 1960), which is nonetheless that the exercise of the urban semiotic competence. If all citizens have a semiotic competence, the latter can be very different according to their subjectivity. Different genders, for example, experience city spaces in different ways, due to matters of value creation, but also of safety. The same can be said for all demographics and, ultimately, for all individuals: their unique combination of perspective and experience will give birth to countless different urban readings.

In order to read the city, however, citizens need to move through it, and this movement, as claimed by de Certeau, is a form of enunciation. In other words, moving in the city, because of the bodily nature of the subject, is a way of reading it out loud. Bystanders see how other people move and at in the urban spaces, and therefore infer their readings of the city. Crossing a road when the red light is on, then, becomes a statement 
defiance or disregard of the rules. In this sense, acting in the city means inserting one owns subjectivity in it, changing the city in the eyes of the people around.

On the other hand, it is also possible to physically alter the city. "Writing the city" - building, affixing, smearing, demolishing, uprooting, colouring the objects of the city - assumes often a character of rewriting, of superimposing new writing to an existing text. Writing the city means adding layers of meaning, removing and filling gaps, rectifying what already exists in an environment that is then continuously modified. It is, therefore, a form of bricolage that re-works already existing elements and materials. The city, in a nutshell, is formed by a material substrate produced by the superposition of multiple inscriptions which, in turn, become the substrate and support of new writings, whether they are strategic or simply the traces of the human activities that take place in the urban space.

We can distinguish two polarities of city-writing: one close to the idea of the palimpsest (a medieval manuscript from which the writing has been scraped off so that the page could be reused for another document), involving the removal, at least partial, of the pre-existing substrate and the construction of something new, and one characterized by a kind of maquillage in the name of recovery, based on the transformation or resemantisation of existing urban objects. This second, more common, form of rewriting is exercised both by the power - for example with regard to the transformation of a convent in a hospital or in an ancient palace into a town hall - and by peripheral social actors - which occupy buildings, become squatters, camp in parks, write on the walls, and so on. These rewritings, even when with practical purposes, cannot be regarded as exclusively functional: instead, they always have a highly communicative character. On the one hand, they affect the general meaning of the object that is resemantised, and, on the other hand, they become a way for individuals or for social political or religious groups, to engrave themselves within the city-text, to leave a trace, to represent their existence within the universe that the city represents.

\section{The right to write the city}

The social, cultural and political relevance of the city-text entails that the action of writing the city is by all means an exercise of power. Established power groups - political, religious, economical - will struggle for the possibility of shaping the city and will often exclude the majority of 
citizens from doing it. It is not a surprise, then, that the struggle against power often becomes a struggle for the right to write the city. The latter is an extension of Lefebvre's droit à la ville, the right to the city (1968). The French philosopher claims that capitalism is reducing citizens to commodities, and that it is of paramount importance to "rescue" them and give them a role as protagonist in the city spaces.

Political opponents and marginalized groups, then, try and occupy public and private buildings, changing their meaning be it for a protest or for squatting. Street art and graffiti, even the most innocuous ones, are therefore always a political statement, reclaiming a "right of authorship", engraving messages or even just their presence of the writers into the cityscape.

This struggle for the "right to write the city" is probably as old as the first human settlement. The purposeful actions that citizens take to reclaim and modify the urban spaces are often gathered under the umbrella term "DIY urbanism", a concept that indicates "small-scale and creative, unauthorized yet intentionally functional and civic-minded 'contributions' or 'improvements' to urban spaces" (Douglas, 2014). Alternative or adjacent terms have also been proposed - amongst which are: Tactical Urbanism (see Lydon 2012), Guerrilla Urbanism, and many others however the definition of these actions is still rather vague. The main common characteristics can be identified with the small scale of the intervention and the self-help, grassroot ideology behind them.

The actions of DIY urbanism are not new, and similar initiatives can be traced back for centuries. The novelty, then, is the creation of a shared tactical and ideological framework, gathered around a few key-terms, that contributed to the success of these actions.

In one of the first studies dedicated to DIY urbanism, Finn (2014) defines its three core characteristics: 1) it is realized and paid for by individuals or by small voluntary groups, 2) it attempts to emulate or augment official municipal infrastructure in public spaces and 3) the beneficiary (at least rhetorically) is the general public. Finn claims that most of these actions aim to have a medium/long-term impact and attempt to solve a local urban problem. The "arsenal" of DIY urbanism is rather vast, and include tactics such as: "chair bombing", i.e. creation of self-made benches in response to a lack of seating; "guerrilla gardening", which involves planting unauthorized gardens in city parks,; and "seed bombing" which entails the creation of small "bombs" full of seeds, compost and powdered clay that are thrown over fences or into vacant spaces and left to bloom. 
These actions are often "innovative, sophisticated, and low-cost solutions to difficult or unaddressed urban problems" (Finn 2014, 381-382), however they are not unproblematic. They work as a sort of "vigilante urbanism" that can very well interfere with cities just as vigilante justice vexes law enforcement officials (ibid., 382).

DIY urbanism as a form of city writing, however, is not the only way for citizens to reshape the urban fabric. As we have stated above, every action in the city is a form of enunciation. The way we commute, we interact with other people, the actions we chose to undertake within the city modify it in the eyes of the bystanders, with effects that can be far more persistent than the action itself.

In this possibility of enunciating cities lays the disrupting efficacy of urban play. Playing in the city is changing the city. It means claiming the public spaces as playgrounds, proposing a non-utilitarian reading of the urban spaces, inviting to take part in new forms of relationship with the other inhabitants, no longer based on citizenship, but on playership.

\section{The Ludicisation of the City}

If play is such a strong force for changing cities, and if the idea of a playful attitude towards urban spaces has long being considered, while we are seeing this phenomenon growing stronger today?

The answer is probably to be found in the so-called ludicisation of culture - a cultural trend that sees games and play occupying a more and more central place in our society.

This change was anticipated by Ernst Lurker in his essay Play Art: Evolution or Trivialization of Art? (Lurker 1990) where he claimed that society's attitudes toward play was about to undergo an important transformation.

Brian Sutton-Smith too stated that the world was becoming more playoriented and that "the ludic turn in Western culture, the shift in sensibility that makes it possible to see contemporary living through the lens of play" (Sutton-Smith, 1997 in Henricks, 2017, 7).

We call this playful turn the "ludicisation of culture": a cultural trend (dating probably from the Enlightenment, from Rousseau's and Shiller's works on education) that see playfulness and games become more and more culturally relevant. This trend has accelerated thanks to the enormous economic and cultural success of digital games and nowadays 
all kinds of games, as well as other forms of play, enjoy a new cultural centrality. Today, games are perceived as socially and culturally relevant, they become ways to describe our reality as well as models to shape our reality (Thibault 2017). The cultural boundaries that used to define the contexts in which play can may be acceptable are being deeply redefined (Idone Cassone, 2017) and now we are living in an "era of playful expression, a time in which play has become a cultural, social and economic centerpiece" (Sicart, 2018, 262).

Several terms have been proposed to describe this phenomenon. Raessens (2006) calls it "ludification of culture", while the expression "gamification of culture" has also been proposed. I decided to use "ludicisation", a term introduced by Bonenfant and Genvo (2014) as, differently from "ludification" is not based on the action of making something more playful or game-like (from the Latin facere, to do), but indicates a process, the one that is leading to a different perception of what is play and what is not. Ludicisation then indicates how play is more and more perceived as a fundamental tool for describing and understanding contemporary culture. Ludicisation, in other words, means that society rethinks itself as playoriented (Thibault 2016).

We have claimed that cities are, among other things, a mean through which a culture represents itself and its own understanding of the universe. It is not surprising, then, if urban spaces are one of the areas touched by ludicisation. The city, then, becomes a playground, host of playful activities and interactions that escape from the places traditionally devoted to them. The very enunciation of these cities - the way we live them, cross them, interact with them - is becoming more and more playful. Urban practices that used to be absolutely "serious" are now reformulated or modified in order to follow this cultural change. These activities generally take the form of pervasive play practices, as they involve a widening of the boundaries (spatial, temporal and social) of the play activity, which will then involve large portions of public space, moments not institutionally devoted to play and unsuspecting passers-by (Montola et al 2009).

As mentioned before, I call these sorts of actions: urban gamification. The term "gamification" traditionally indicates the attempt of using game design elements and inducing a playful behaviour in order to boost user engagement and increase the efficacy of non-game activities, both digital and not. The concept (born in the digital media industry between 2008 and 2010) has been applied especially to education and learning (Salen 2007), business (Werbach \& Hunter 2012) and health (McGonigal 2011). 
Analytic approaches and theoretical frameworks are quite recent in the field and are articulated around a perspective focusing mainly on defining "game elements" and their efficacy (Deterding et al 2011) or on redefining gamification on the basis of the participant experiences (Huotari \& Hamari 2015). This second approach seems to be most efficient: as a recent study (Hamari et al 2014) points out, gamification's positive effects are greatly dependent on the context and on the final users of the activity.

Urban gamification, then, is based on the fact that introducing a playful behaviour in urban spaces - which are traditionally considered "serious" spaces - reshape the perception that the citizens have of the city. It gamifies it.

The choices that lie behind the use of strategies of urban gamification may vary. Some of them are bottom-up actions fuelled by the desire of (re)appropriating public spaces or to send a political message, while others are merely marketing techniques put in place by fashion-following companies. What all they all have in common, however, is the desire to rewrite the city, to reshape it, to engrave oneself in it, to renew it by resorting to the energy and the ability to motivate people that emanates from play. In the next paragraph we will engage a few examples.

\section{Some Examples of Urban Gamification}

There are several interesting examples of gamification of urban spaces that make use of performance, artefacts, games and/or digital tools to gamify the city. One of the oldest and most effective practices of urban gamification, are Pride Parades. They were born 50 years ago, but these marches with colourful and carnivalesque playful features did not lose any of their subversive power and are still capable of attracting enthusiastic participation and reactionary hatred (Johnston 2007). The centrality of the theme of body, in the fight for LGBTI+ rights and equality, is mirrored in the use of the body in the public space of the city. The playful and disruptive ways in which the bodies are often dressed, move and dance in the city streets are of central importance for the efficacy of these manifestations.

A similar point can be made for flash mobs, which are probably one of the most widespread practices of urban play. Flash mobs take place in the heart of the city and involve the sudden gathering of a crowd of people executing an unusual performance with a playful flavour. Flash mobs invade the space of traditional events: they have the same purposes and settings of protest marches, sit-ins, and fairs and they often replace them 
(Turco 2012). During a flash mob performance, the spaces of the city are transformed in improvised stages for shows that involve masking, carnivalesque features, and surrealisms. Flash mobs, then, are a semiotic device acting on the border between everyday reality and play: viewers of a flash mob become players without their knowledge. The communicative effectiveness of these practices is based on this interpretative disorientation: the temporary inability to distinguish between semiotic domains. Flash mobs play with the status of playfulness, they omit the message "this is play" (Bateson 1955) and entrust it to an implicit metacommunication: passers-by have to activate their competence in the semiotic domain of play in order to be able to correctly interpret the scene unfolding before their eyes.

Another relevant example is Park(ing) day, an activity sometimes considered as DIY urbanism (Lyndon 2012), despite its ephemeral nature. Born in 2005 in San Francisco, the initiative - promoted by the art and design collective Rebar - involves renting a metered municipal parking space for a few hours and, instead of parking a car in the spot as it would be supposed to be, creating a small urban park to chill in. The concept is quite successful and since 2005, similar experiments are held the third Friday of September every year in many different cities around the world. These pop-up parks are ephemeral, and they clearly do not aim at changing the urbans spaces directly. The objective of these manifestations, instead, is to generate critical debate around how public space is created and allocated, and to improve the quality of urban human habitat. Park(ing) day has a strong playful component of pretend play. Its pop-up parks are in fact "masks" applied on the parking lot, and not real, sustainable parks. The participants that chill, meditate or play guitar in the parks are also, in part, pretending, as they are well aware of the situation. Finally, park(ing) day also proposes a sort of make believe to the passersby, interrogating them on how it would be to have more green spaces in the city.

Not all examples of urban gamification are bottom up, and a number of coordinated projects also exist. Fun Theory from Volkswagen implements a more "classic" take on gamification trying to devise ways of influencing people's behaviour through playful activities. Piano Stairs, for example, aims at encouraging people to take the stairs by allowing them to play music while doing it, The World's deepest bin with its funny sound tries to make throwing away trash fun and the Speed camera lottery encourages safe driving by pairing to fines also a prize for those who respect speed limitations. Another interesting platform is Playable Cities which promote projects that make high use of technology in order to rewrite city experiences, for example recording the shadows of passers-by and 
projecting them a few minutes late (Shadowing) or allowing citizens to exchange texts with street-furniture (Hello Lamp post).

Our last example is a fully-fledged game: Cruel 2 B kind. It is an experimental urban game created by Jane McGonigal and Ian Bogost in 2006. During the game, the players are scattered throughout the city with the objective of finding other players and "killing" them using a series of "weapons": various acts of kindness assigned to them by the organisers. If a player or a team are killed, they will have to join the team that killed them. The point of the game is that, as players do not know their targets, they will end up walking the city complimenting complete strangers about their shoes, or mistaking them for celebrities, effectively spreading kindness around. This is, in fact, the objective of the game: "Will innocents be caught in the cross-fire? Oh, yes. But when your secret weapon is a random act of kindness, it's only cruel to be kind to other players" (McGonigal \& Bogost 2006). Urban games, by definition, use the city spaces as their playground. Cruel 2 B Kind, however, does something more: by requiring players to interact with strangers it transforms the city to a playground, it makes it a space of play for everyone who is there.

\section{Urban Gamification in Digital Representations}

Contemporary cities extend beyond their physical reality and are caught in a complex net of digital prosthesis and representations. In the last decade, a great effort has been made to digitize and map the space - and in particular the urban space - especially by private actors (Hudson-Smith 2007). The resulting digital maps pervade our everyday life. These maps, however, are more than mere reflections of the city. As claimed by Ferraro (2008), the cartographic representation of the city provided by a satellite navigation system involves a shift in the balance of power between the city and its representation.: these digital maps change before our eyes in accordance to our behaviour they watch us, reconfigure themselves and provide information of all kinds. Services such as Google Maps provide a complete and detailed mapping of the urban space, which not only incorporates the meta-linguistic signs of the city (street names etc.) but includes also numerous hypertextual links to the Web (homepages of hotels, restaurants and shops, user ratings of tourist attractions, pictures of the places of interest and so on). Social network websites, on their side, allow tagging and positioning mechanisms that draw new connections between the city and online content (Nam \& Kannan 2014). The digital map, then, acquires the status of a prosthesis of the city. 
Parallel to these processes of mapping, there is also an ongoing digital transposition or translation of urban spaces. In Google Street View urban areas are meticulously photographed, reconstructed and made available on the Web. This massive work of translation tries to recreate the city in all its semiotic richness, fixing its surfaces in digital images and reproducing virtually its paths. This virtual city is frozen in a collage of different moments and immutable paths, but nevertheless manages to roughly simulate the experience of moving through the city space.

Smartphones, furthermore, combine these digital maps and recreations with the ability of observing the surrounding environment through the lens of a camera. In this way, they become a key to multiple new ways of reading city spaces: augmented reality allows devices to offer their users information about their location, add new layers of meaning to the city spaces, even offers to the users themselves the possibility to leave comments and virtual graffiti while interacting with their surroundings through the screen. Augmented reality often combined with digital maps is often implemented in digital games such as Ingress or Pokémon Go, effectively gamifying the act of moving through the city, with consequences that exceed the boundaries of a simple play activity (Boulos et al 2017).

In order to understand urban gamification, we must explore also its effects on the digital dimensions of the city. Digital urban gamification often acts as a sort of playful resistance to the digitisation of urban spaces by private companies. It is formed by a bottom-up set of activities, which operates on both the enunciation and writing level of the city.

Enunciating a digital map equals to navigate through it while leaving some traces: taking screenshots or tagging locations. Users don't always "read" digital maps for practical matters, and sometimes use them creatively. The digital representations of the city, then, are used to pursue playful aims, in open contradiction with their functional use proposed by their creators. Apple maps failed attempts of reconstructing a 3D rendering of its maps, for example, has become an excuse for "hunters of curiosities" to search the map for the most weird or funny-looking mistakes that will be immediately shared on-line and sometimes become viral memes.

The creation of these maps and of these reproductions of cities is not immune to these playful escapades. Just like for real cities, individuals often try to engrave their presence in digital maps and translations - they try to leave a mark, to claim some role as co-authors. On Google Street View, despite the attempts to keep secret its path, the Google car often 
encounters photobombers in its way: people dressed as monsters, puppets arranged to look like living beings, fake murder scenes - a real carnival that is then fixed into the virtual city. In some of the most notable cases, photobombers may "aim high", realizing some extensive works to be taken up by satellite and immortalized in Google Earth, such as Where on Earth is Waldo? an installation realized by Melanie Coles in Vancouver, that compares the complexity and semiotic noise of the satellite-made map of Earth with the famous puzzle-books by Martin Handford.

Finally, the maps and digital reconstructions of the urban space also become subject of forms of digital writing. The maps can be transformed into supports and basis to build simple digital games. in Street View Zombie Apocalypse, for example, the players can move in first-person in the streets portrayed by Google Street View, trying to escape poorly drawn zombies. Similarly, there are games that allow players to participate in some basic motor racing simulators on a virtual path overlapping the streets of Google maps. In some rare cases these games are able to annoy the companies owning the maps enough to trigger their actions. It has been the case of Google Shot View, a modification of Street View that allowed the player to walk around the virtual map armed of a combat rifle, immediately sued and shut down by Google.

These playful interpretations, reinterpretations and rewritings of maps and virtual representation of the urban area are, as we mentioned, different from the aims pursued by the company that owns them. We are facing, thus, a conflict of power similar to those of the real cities. These virtual and digital maps are contributing in a more and more crucial way to influencing the readings and interpretations of the city by its inhabitants, and the latter appear to resent the monolithic private power that controls them, sometimes resolving to use subversive playfulness as a tool to question it and reclaim, albeit in a, ephemeral way, a right to the virtual city.

Nevertheless, not all forms of urban digital gamification are grassroot. The private owners of the maps themselves are also exploiting the drive of ludicisation in profitable ways: implementing games or Easter eggs in their maps or creating new games upon them altogether. After all, both Pokémon Go and Ingress are owned by Google.

It is interesting to notice how there is also a movement in the opposite direction: digital reconstructions and mappings of real cities for game purposes sometimes find new uses. It is the case of the series Assassin's Creed (Ubisoft, 2007-present) famous for digitally complex reproductions of ancient cities. In the two last games (Odyssey and Origins) a particular mode called "Discovery Tour" was implemented (Politopoulos et al 2019). 
In this mode the players do not have the usual objectives and enemies, but can simply navigate the city as tourists, discovering its beautiful reconstruction. Nevertheless, the game still allows players to climb on the buildings and move on the roofs in a parkour-like way, therefore encouraging an use of the city that is inherently playful. Interestingly, David Belle, considered the founder of parkour, underlined in an interview ${ }^{1}$ how this way of interacting with the city is playfully disruptive even in video games: the players often stop focusing on their missions, for the pure pleasure of running free on the roofs of the city.

\section{Conclusions}

In this paper we have seen how the city, a semiotic machine stupendously complex, as well as its innovative digital representations, is increasingly subject of playful resemantisations. Play can infiltrate several contexts and spaces, and propose new meanings, new constraints, new strategies and new motivations.

A meaning-centred approach to urban areas can be very useful to conceptualise the types of actions that can be undertaken in order to use play and to describe how they can influence the readings and interpretations of said spaces. The framework of urban gamification, then, can be an important tool to understand the way in which contemporary cities and the practices that take place within them are changing and becoming increasingly ludified.

This framework is meant to be a tool of analysis for researchers and stakeholders interested in understanding the role that gamification is playing in the urban spaces. At the same time, the conceptualisation of urban gamification can also be used in a prescriptive manner: play is a tool for reappropriating urban spaces and to fight the anonymity of cities brought by the gentrification and partial defuncionalisation of space and understanding how it affects these spaces can inform new strategies for reclaiming them.

Future research on this topic should, on the one hand, diversify the case studies in order to analyse as many types of urban gamification as possible and, on the other hand, start to build categories, typologies and a metalanguage dedicated to the study of this phenomenon. Urban gamification as a phenomenon is probably going to increase its relevance

${ }^{1}$ Available at: https://www.youtube.com/watch?v=9LS2Ewe8FTI 
in the near future, and hence the need for appropriate tools to understand it and, eventually, to design it.

\section{Acknowledgement}

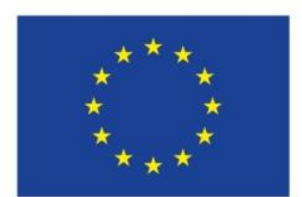

This project has received funding from the European Union's Horizon 2020 research and innovation programme under the Marie Sklodowska-Curie grant agreement No 793835”.

Marie Skłodowska-Curie Actions

\section{References}

Bateson, G., (1955) A theory of play and fantasy. Psychiatric research reports.

Berman, M., (1982) All that is solid melts in the air. The experience of modernity. Simon and, New York.

Bonenfant M. \& Genvo, S. (2014) "Une approche située et critique du concept de gamification". Sciences du jeu 2

Boulos, M.., Lu, Z., Guerrero, P., Jennett, C., \& Steed, A. (2017) "From urban planning and emergency training to Pokémon Go: applications of virtual reality GIS and augmented reality GIS in personal, public and environmental health", International Journal of Health Geographics, 16:7.

Certeau, M. De, (1980) L'invention du quotidien, 1. Arts de faire, Union générale d'éditions, Paris.

Cervelli P. and F. Sedda (2006) "Zone, frontiere, confini: la città come spazio culturale", in Marrone G. and I. Pezzini (eds.), Senso e metropoli. Per una semiotica posturbana, Meltemi, Roma, pp. 171-192.

Debord, G. (1957) "The naked city" in Asger J. (ed.) The Situationist International: A User's Guide.

Deterding, S. Kahled, R., Nacke L. and D. Dixon (2011) "Gamification: Toward a Definition” in CHI 2011, May 7-12, 2011, Vancouver.

Douglas GCC. (2014) "Do-it-yourself urban design: The social practice of informal improvement through unauthorized alteration", City and Community 13(1): 5-25. 
Ferraro, G. (2008) “Oltre l'idea di città", Lexia 1-2, Aracne, Rome, pp. 215-222.

Finn D. (2014) "DIY urbanism: implications for cities". Journal of Urbanism: International Research on Placemaking and Urban Sustainability 7(4): 381-398.

Floch, J.M. (1990) Sémiotique, marketing et communication : Sous les signes, les stratégies, PUF, Paris.

Hamari, J. Koivisto J. and H. Sarsa (2014) "Does gamification work? a literature review of empirical studies on gamification" in 2014 47th Hawaii International Conference on System Sciences, pp. 3025-3034.

Henricks, T. (2017) "Foreword" In Sutton-Smith, B. (2017) Play for Life. Play Theory and Play as Emotional Survival. Compiled and edited by Charles Lamar Phillips and the editors of the American Journal of Play, The Strong.

Hudson-Smith, A. (2007) "Digital urban - the visual city". UCL Working Papers Series 124.

Huotari K. and Hamari J. (2015) "A definition for gamification: anchoring gamification in the service marketing literature", Electronic Markets 27(1), pp. 21-31.

Idone Cassone, V. (2017) "Through the Ludic Glass. A cultural Genealogy of Gamification", in Proceedings of Academic MindTrek 2017 Conference (Tampere). New York, ACM Press. DOI: $10.1145 / 3131085.3131120$

Ivain, G. (1958) "Formoulaire pour un urbanisme nouveau", Internationale situattioniste 1, Bulletrin céntral, Paris.

Johnston, L. (2007) Queering tourism: Paradoxical performances of gay pride parades. Routledge.

Lange, Michiel de (2015) "The Playful City: Using Play and Games to Foster Citizen Participation." In Social Technologies and Collective Intelligence, edited by Aelita Skaržauskienè, 426-434.

Lefebvre, H. (1968) Le droit à la ville. Anthropos: Paris.

Lotman, JM. (1998) "L'architettura nel contesto della cultura", in S. Burini (ed.) Il girotondo delle muse. Saggi sulla semiotica delle arti e della rappresentazione, Moretti and Vitali Editori, Bergamo.

Lotman, JM (2011) "The place of art among other modelling systems" Sign Systems Studies 39(2/4), pp. 251-270. 
Lurker, E. (1990) "Play Art: Evolution or Trivialization of Art?" Play \& Culture 3: pp. 146-167.

Lynch, K. (1960) The Image of the City, MIT press Cambridge.

Lydon M (2012)(ed.), Tactical Urbanism, vol. 1, n.d. issuu.com/streetplanscollaborative/docs/tactical_urbanism_vol.1

Mastroianni, R. (2013)(ed.) Writing the city. I Saggi di Lexia, Aracne, Rome.

McGonigal, J. (2011) Reality Is Broken: Why Games Make Us Better and How They Can Change the World, Penguin Books, London.

McGonigal J, Bogost I (2006) Cruel 2 B Kind. www.comeoutandplay.org/2006/08/06/ cruel-2-b- kind/

Montola, M., Stenros, J. and A. Waern (2009) Pervasive Games. Theory and Design, Morgan Kaufmann Game Design Books, San Francisco.

Nam, H., \& Kannan, P. K. (2014) "The informational value of social tagging networks". Journal of Marketing, 78(4), pp. 21-40.

Nijholt, A. (2017) Playable Cities. Springer, Singapore.

Politopoulos, A., Mol, A. A., Boom, K. H., \& Ariese, C. E. (2019). "History Is Our Playground": Action and Authenticity in Assassin's Creed: Odyssey. Advances in Archaeological Practice, 7(3), 317-323

Salen, K. (2007) The Ecology of Games: Connecting Youth, Games, and Learning, MIT press, Cambridge, 2007.

Sicart, M. (2018) "Quixotean Play in the Age of Computation". American Journal of Play, 10(3).

Stevens Q. (2007) The ludic city: exploring the potential of public spaces. Routledge.

Sutton-Smith, B. (1997) The ambiguity of play, Harvard University Press, Cambridge.

Thibault, M, (2016) "Lotman and play: For a theory of playfulness based on semiotics of culture" Sign Systems Studies 44(3): 295-325.

Thibault, M, (2017) "Play as a Modelling System - a Semiotic Analysis of the Overreaching Prestige of Games", Proceedings of the 1st International GamiFIN Conference, CEUR-WS: 105-110.

Thibault, M. (2019) "Towards a Typology of Urban Gamification" Proceedings of HICSS 2019, DOI: http://hdl.handle.net/10125/59588 
Turco, F. (2012) "Flash mob: quando la performance diventa strumento di protesta", Lexia 13-14, Aracne, Rome, pp. 305-319.

Volli, U. (2005) Laboratorio di semiotica, Laterza, Bari-Roma.

Volli, U. (2008) "Il testo della città — problemi metodologici e teorici", in M. Leone (ed.) Lexia 1-2, Aracne, Rome, pp. 9-12.

Werbach K. and D. Hunter (2012) For the win, How Game Thinking Can Revolutionize Your Business, Wharton Digital Press, Philadelphia.

Wittgenstein, L. (1953) Philosophical Investigations, E. Anscombe (trans.) Palgrave Macmillan: New York. 